\title{
Interfacial Reactions at Early Stages of Mn Addition to Liquid Fe
}

\author{
Pengcheng YAN, Lieven PANDELAERS, Muxing GUO* and Bart BLANPAIN \\ Department of Metallurgy and Materials Engineering, KU Leuven, Kasteelpark Arenberg 44 - Bus 2450, BE-3001 Leuven, \\ Belgium
}

(Received on November 1, 2013; accepted on January 14, 2014)

\begin{abstract}
$\mathrm{Mn}$ is an important alloying agent in steelmaking. Its interaction with liquid Fe during the alloying/deoxidation influences Mn recovery yield and steel cleanliness. We have experimentally studied the interfacial reactions at the early stages of $\mathrm{Mn}$ addition to liquid Fe containing various amounts of dissolved oxygen and sulphur. Diffusion couples were obtained by bringing liquid Fe into contact with solid Mn for various durations. After quenching these diffusion couples, the interdiffusion of Fe/ $\mathrm{Mn}$ and the formation of a reaction zone at the Fe/Mn interface were investigated. The measured $\mathrm{Mn}$ concentration profile at the interface was fitted with a theoretical model based on Fick's second law. The magnitude of the fitted apparent diffusion coefficient suggested that a layer of Fe solidified around the cold Mn. While enclosed by this Fe shell, the Mn was partially molten due to its low melting temperature. The formation of oxysulphide inclusions was observed at the Mn-rich side of the interface, while an inclusion free zone was detected in the Fe-rich side close to the interface. Based on these experimental findings and theoretical calculations, the mechanisms governing the Fe/Mn interdiffusion and the inclusion free zone formation were proposed.
\end{abstract}

KEY WORDS: interfacial reaction; $\gamma$-FeMn; inclusions; diffusion couple.

\section{Introduction}

Manganese is an important alloying agent in steelmaking. Its addition to steel products improves their hardness and wear resistance. $^{1,2)} \mathrm{Mn}$ is also used as deoxidation and/or desulphurisation agent in steelmaking due to its strong affinity for oxygen and sulphur. ${ }^{3)}$ The deoxidation and/or desulphurisation products, i.e. Mn-containing inclusions (e.g. $\mathrm{MnO}$ and $\mathrm{MnS}$ ) can be further utilized to minimize the harmful and maximize the beneficial effects of inclusions. ${ }^{4-6)}$ For instance, $\mathrm{MnS}$ can act as a lubricant between hard oxides and the steel matrix as a result of its low hardness and low melting temperature, thereby reducing their detrimental effects. ${ }^{4,5)}$ Moreover, Mn-containing inclusions (e.g. MnO$\mathrm{SiO}_{2}-\mathrm{TiOx}-\mathrm{MnS}$ type) are recognized as one of the most effective inclusions to act as nuclei for intragranular acicular ferrite (IGF), ${ }^{6}$ which results in a reduced grain size and consequently improves the mechanical properties of these steel products. In particular, the Mn-depleted zone formed around Mn-containing inclusions can induce the IGF formation.

During ladle refining, pure $\mathrm{Mn}$ and/or FeMn alloy are added to the molten steel. To maximize the beneficial effect of $\mathrm{Mn}$, its content has to be precisely controlled. Due to the high vapour pressure of $\mathrm{Mn}$, its recovery yield can be significantly influenced by initial interactions with liquid Fe. ${ }^{7)}$ More importantly, the formation of oxide/sulphide inclusions at the early stages of Mn deoxidation (and/or alloying) determines the inclusion characteristics (such as inclusion size and size distribution, number density, morphology and

* Corresponding author: E-mail: muxing.guo@mtm.kuleuven.be DOI: http://dx.doi.org/10.2355/isijinternational.54.1209 chemistry), and hence the steel properties. ${ }^{8)}$ To facilitate quantitative inclusion engineering, a deep understanding of their nucleation and growth, as well as thorough insight in the interdiffusion and interfacial reactions between Mn addition and a steel melt is required.

Interfacial reactions between alloying agents and molten steel have been investigated by several groups. ${ }^{9-13)}$ Argyropoulos et al. studied the dissolution of alloys (FeSi and Ti) by immersing them in molten steel. ${ }^{9,10)}$ They found that the dissolution consists of two stages, viz. the steel shell period and free dissolution period. During the former a layer of steel solidifies on the surface of the cold alloy. As the alloy is heated, this shell starts to melt. Free dissolution refers to the alloy dissolution in the liquid steel after the shell has melted. The initial stages of Al deoxidation were examined by Van Ende et al. with a liquid metal suction method. ${ }^{11,12)}$ They observed that the reaction zone was composed of successive layers of $\mathrm{Fe}-\mathrm{Al}$ intermetallic compounds, as predicted by the $\mathrm{Fe}-\mathrm{Al}$ phase diagram. $\mathrm{Al}_{2} \mathrm{O}_{3}$ inclusions formed in the $\mathrm{Fe}-\mathrm{Al}$ reaction zone. It was demonstrated that the $\mathrm{Al}$ addition (around $5 \mathrm{~g}$ ) melted completely before the shell (around $10 \mathrm{~g}$ ) had molten. Pandelaers et al. focused on the interfacial reactions during Ti dissolution in molten steel, ${ }^{13)}$ showing that a liquid reaction zone is formed between the addition and the shell when their interface reaches the lowest eutectic temperature of the Fe-Ti system. Even though the melting point of $\mathrm{Ti}$ is higher than that of $\mathrm{Fe}$, internal dissolution of $\mathrm{Ti}$ and $\mathrm{Fe}$ takes place, governed by coupled heat and mass transport. Pande et al. compared the dissolution behaviour of different Ti sources, i.e. Ti, FeTi35 and FeTi70 in liquid Fe. They found that FeTi35 was quickly dissolved due to its low melting temperature, 
and therefore less time was available for the modification of $\mathrm{Al}_{2} \mathrm{O}_{3}$ inclusions originally present in the FeTi alloy. FeTi70 was more easily dissolved than pure $\mathrm{Ti}$, while its impurity elements like $\mathrm{Al}$ and $\mathrm{Ca}$ resulted in the formation of $\mathrm{Al}-\mathrm{Ti}-$ $\mathrm{O}$ inclusions. ${ }^{14)}$ Literature on the Mn/liquid steel interfacial reactions, however, is limited. Specifically for the early stages of Mn deoxidation, knowledge is lacking concerning the microstructural development of the $\mathrm{Mn} /$ liquid steel interfacial region at high temperature, and concerning the reactions and inclusion formation at the $\mathrm{Mn} /$ liquid steel interface shortly after the deoxidation stage.

In this study the interactions between Fe and Mn shortly after the deoxidation stage were investigated by microstructural analysis of quenched diffusion couples, which are formed by bringing liquid Fe into contact with solid Mn for various durations. The interactions, i.e. Mn melting, interdiffusion and the nature of the phases at the experimental temperature, were identified. These interactions depend on the thermal history, mass transfer and the supersaturation degree, which determine the nucleation and growth of the inclusions. The influence of the interaction time and the dissolved oxygen and sulphur content on the Fe/Mn interdiffusion and formation of an inclusion free zone have been evaluated. Based on the experimental results and theoretical calculations, the mechanisms governing the Mn dissolution and the inclusion free zone formation were proposed.

\section{Experimental}

$\mathrm{Fe}_{2} \mathrm{O}_{3}$ and $\mathrm{FeS}$ (reagent grade) were mixed with $100 \mathrm{~g}$ electrolytic $\mathrm{Fe}(99.97 \% \mathrm{Fe})$ in a magnesia crucible. The crucible was then charged into a vertical tube furnace (GERO HTRV 100-250/18, $\mathrm{MoSi}_{2}$ heating elements) and the mixture was melted at $1600^{\circ} \mathrm{C}$ under Ar atmosphere. The $\mathrm{Ar}$ was purified by passing over $\mathrm{Mg}$ chips at $550^{\circ} \mathrm{C}$. The oxygen content in the off-gas was measured with a solid state ceramic oxygen sensor (Rapidox 2100), yielding a typical value of about $10^{-18} \mathrm{ppm}$. After the Fe was melted, the melt was stabilized at $1600^{\circ} \mathrm{C}$ for $60 \mathrm{~min}$. A small piece of $\mathrm{Mn}$ (around $3 \mathrm{~g}$ in cubic shape, 99.8\% Mn) was placed in a quartz tube. The end of the quartz tube was narrowed in order to maintain the Mn piece inside. The quartz tube with the Mn piece was then quickly introduced into the furnace and lowered into the melt (Fig. 1(a)). A small volume of liquid $\mathrm{Fe}$ was sucked and brought into contact with $\mathrm{Mn}$ for a designated interaction time (Fig. 1(b)). Thereafter, the tube was rapidly withdrawn from the furnace and quenched in water. The detailed conditions for each test are listed in Table 1.

The lower part of the obtained diffusion couple, which was Fe without Mn (Fig. 2(a)), was cut into small pieces $(0.5-1.0 \mathrm{~g})$ and cleaned with acetone in an ultrasonic bath. At least two pieces of Fe were analysed with LECO combustion analysis (TC-400 and CS-230) for total oxygen (T.O) and total sulphur (T.S) measurement. The measured values (average of two samples) are listed in Table 1. Since the impurity level of the electrolytic Fe was negligible, the measured T.O and T.S was considered to be, respectively, the dissolved [O] and [S] at experimental temperature. The upper part of the diffusion couple was mirror polished and subjected to microstructural characterization using electron

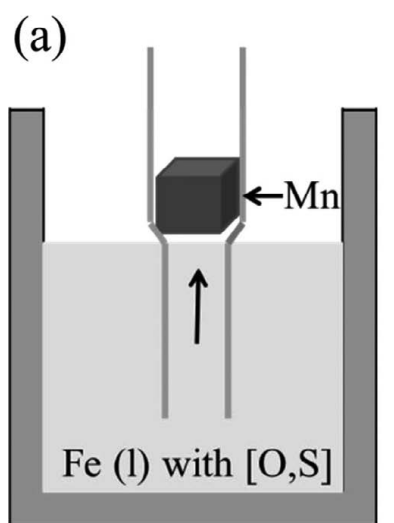

(b)

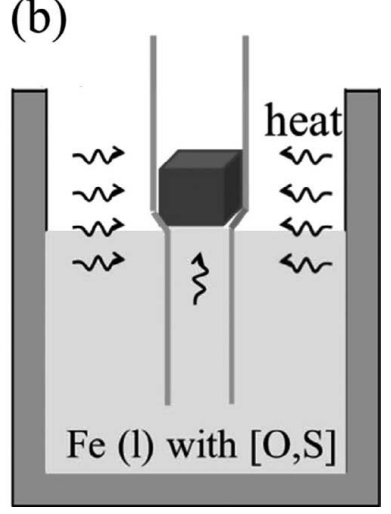

Fig. 1. Experimental set-up and procedure: (a) introducing the quartz tube into the melt and (b) bringing liquid Fe into contact with $\mathrm{Mn}$.

Table 1. Experimental conditions, where T.O and T.S represent total oxygen and sulphur content in liquid Fe.

\begin{tabular}{cccc}
\hline & & \multicolumn{2}{c}{$\begin{array}{c}\text { Composition } \\
\text { (ppm in weight) }\end{array}$} \\
\cline { 3 - 4 } Test No. & Contact time (s) & T.O & T.S \\
\hline $1-\mathrm{a}$ & 2 & 23 & 0 \\
$1-\mathrm{b}$ & 5 & & \\
$1-\mathrm{c}$ & 10 & 250 & 140 \\
\hline $2-\mathrm{a}$ & 2 & & \\
$2-\mathrm{b}$ & 5 & 489 & 444 \\
$2-\mathrm{c}$ & 10 & 955 & 0 \\
\hline 3 & & 34 & 505 \\
\hline 4 & 5 & 1657 & 3570 \\
\hline 5 & & &
\end{tabular}

probe microanalysis (FE-EPMA, JXA-8530F). Phases were identified using electron backscatter diffraction (EBSD, FEI XL30).

\section{Results and Discussion}

\subsection{Overview of the Fe-Mn Diffusion Couple}

The macroscopic examination of the Fe-Mn diffusion couple is shown in Fig. 2(a) (Test 6 as an example). After bringing liquid iron into contact with solid Mn for the predetermined span, the cubic Mn piece has deformed into a cylindrical shape, suggesting that the Mn was melted in this short interaction time. $\mathrm{Mn}$ and Fe make good contact and macroscopically a reaction zone is observed (R-zone in Fig. 2(a)). Figure 2(b) shows a typical overview of the Fe-Mn diffusion couple (BSE image). Three phases, viz. $\alpha$-Mn(Fe) (body-centred cubic, space group I43m), $\gamma$-FeMn (facecentred cubic, space group Fm $3 \mathrm{~m}$ ) and $\alpha$-Fe (body-centred cubic, space group $\operatorname{Im} 3 \mathrm{~m})^{14)}$ are identified by using EPMA and EBSD analysis. Microstructurally, these various phases can be visually distinguished on the BSE image, as indicated by the dashed lines in Fig. 2(b). Small cracks are found to be initiated from the $\alpha$-Mn/ $\gamma$-FeMn interface, which may be due to the $\beta-\mathrm{Mn} / \alpha-\mathrm{Mn}$ transformation. The $\beta$-Mn (simple cubic) is not stable at room temperature, and transforms 


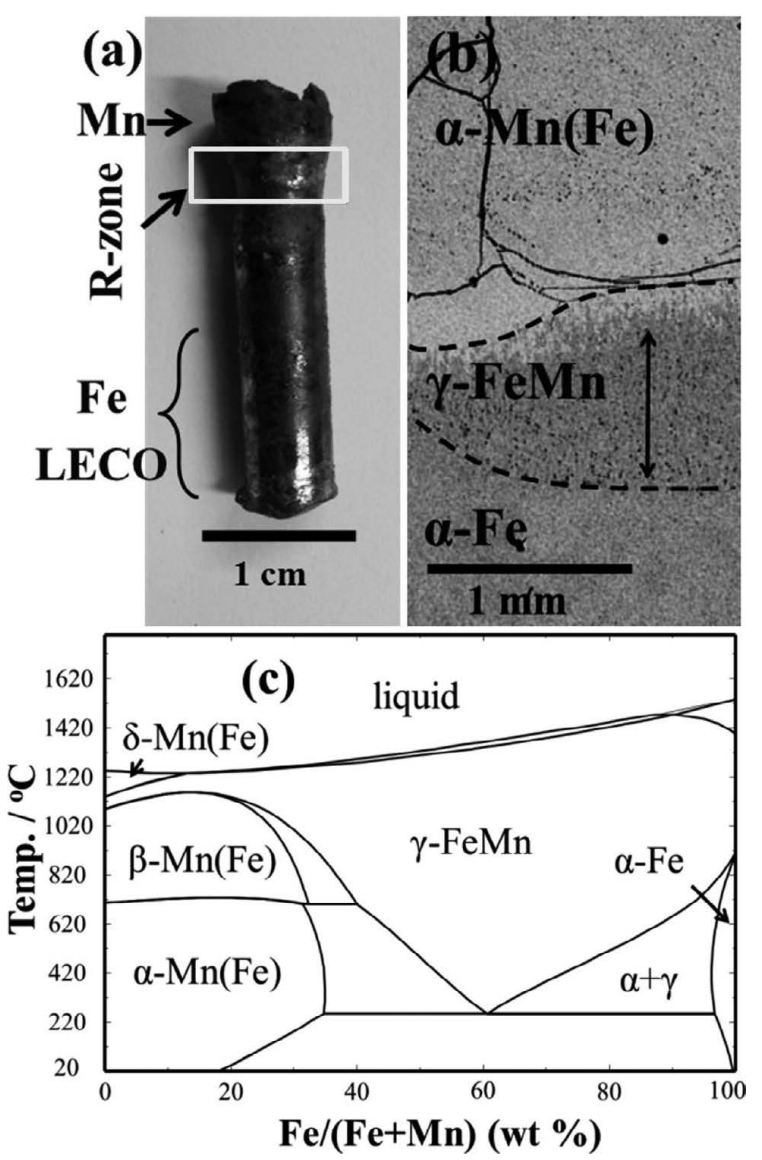

Fig. 2. (a) Macroscopic examination (test 6), where R-zone represents reaction zone and (b) BSE image of $\mathrm{Fe}-\mathrm{Mn}$ reaction zone, and (c) Fe-Mn equilibrium phase diagram as calculated with FactSage.

Table 2. Mn content in Fe-Mn diffusion couple (wt \%).

\begin{tabular}{cccc}
\hline Phase & $\alpha$-Mn(Fe) & $\gamma$-FeMn & $\alpha$-Fe \\
\hline Equilibrium at $25^{\circ} \mathrm{C}$ & $81.4-100$ & - & 0.4 \\
Measured & $70-99$ & $40-70$ & - \\
\hline
\end{tabular}

upon cooling into $\alpha$-Mn (body-centred cubic). The 5\% cell contraction which accompanies this phase transformation may result in cracks. ${ }^{15)}$ The range of Mn content in the phases in Fig. 2(b) is measured with EPMA and listed in Table 2. The compositions of $\alpha$-Fe and $\alpha-\mathrm{Mn}(\mathrm{Fe})$ are in approximate agreement with those expected based on the Fe-Mn equilibrium phase diagram (Fig. 2(c)). The latter is calculated with FactSage, using the FSstel database. Referring to the phase diagram, $\gamma$-FeMn is not stable at room temperature $\left(25^{\circ} \mathrm{C}\right)$ and would be expected to eutectoidally transform upon cooling into $\alpha-\mathrm{Mn}(\mathrm{Fe})$ and $\alpha$-Fe through $\mathrm{Mn}$ redistribution. ${ }^{16)}$ The presence of the pure $\gamma$-FeMn in the diffusion couple, however, is a result of the fast water quenching, which inhibits the Mn redistribution by limiting the Mn diffusion and freezes the 'high temperature' $\gamma$ phase. ${ }^{17)}$

\subsection{The Reaction Zone Development and the Diffusion Process}

3.2.1. Fe-Mn Diffusion Couple without Oxygen and Sulphur Addition

During the experiment, a diffusion couple is formed between a solidified Fe shell and solid Mn (Fig. 2(b)). Inter- diffusion of $\mathrm{Fe}$ and $\mathrm{Mn}$ results in the formation of a reaction zone, in which $\gamma$-FeMn is found between $\alpha$-Fe and $\alpha$ $\mathrm{Mn}(\mathrm{Fe})$ in the quenched sample. Figure 3 shows the microstructural evolution of the reaction zone as a function of interaction time for Test 1 without extra oxygen and sulphur addition. The thickness of $\gamma$-FeMn is slightly larger after 5 seconds interaction (around $2 \mu \mathrm{m}$ in Fig. 3(b)) compared to 2 seconds (around $1 \mu \mathrm{m}$ in Fig. 3(a)), while it considerably increases and reaches $25 \mu \mathrm{m}$ after 10 seconds (Fig. 3(c)). The former indicates that only limited interdiffusion has occurred at the early stages of contact. This is because of (1) the limited time for Fe/Mn interdiffusion and (2) the formation of the solid $\mathrm{Fe}$ shell, i.e. the liquid $\mathrm{Fe}\left(1600^{\circ} \mathrm{C}\right)$ solidifies on contacting the cold $\mathrm{Mn}\left(25^{\circ} \mathrm{C}\right) .^{9-11)}$ This shell inhibits Mn diffusion in the liquid Fe. As can be seen in Fig. 3 , an even $\gamma$-FeMn $/ \alpha$-Fe interface (B-line, where no $\mathrm{Mn}$ is measured at the $\alpha$-Fe side) observed in all samples implies a limited Mn diffusion into solid Fe (as can be seen in Fig. 4), while an irregular $\gamma$-FeMn $/ \alpha-\mathrm{Mn}(\mathrm{Fe})$ interface suggests the presence of a liquid phase. ${ }^{18)}$ This is more obvious after 10 seconds interaction (Fig. 3(c)), where the thick, irregularly-shaped $\gamma$-FeMn layer is indicative for the presence of a liquid zone at the experimental temperature.

Figure 4 shows the measured Mn concentration for various interaction times as a function of the perpendicular distance from the diffusion front, i.e. the B-line in Fig. 3. The total diffusion distance and the thickness of these diffusion layers are measured and listed in Table 3. It should be noted that because the position of the initial $\mathrm{Fe} / \mathrm{Mn}$ interface cannot be deduced from the quenched samples, the x-axis for the different curves lies not necessarily on the same absolute position. Distinct Mn concentration profiles can be observed in three layers, i.e. $\alpha$ - $\mathrm{Mn}(\mathrm{Fe}), \gamma$-FeMn and a thin layer $(<$ $1 \mu \mathrm{m}$ ) between $\gamma$-FeMn $/ \alpha$-Fe (see bright line in Fig. 3). This thin layer is observed in all experimental samples, while its formation mechanism is not fully understood. Literature ${ }^{16,19,20)}$ reports that $\gamma$-FeMn containing $8-40 \mathrm{wt} \%$ Mn can be transformed into $\varepsilon$-FeMn (martensitic phase) during fast cooling. This, however, could not be verified in the present diffusion couple by using EBSD due to the uneven polished surface at the interface. In all samples, the Mn concentration gradient remains quite steep in the $\gamma$-FeMn layer. In the $\alpha$-Mn(Fe) layer the gradient becomes flatter, although it changes considerably with diffusion time. After 10 seconds the reaction zone extends over about $2000 \mu \mathrm{m}$ in $\alpha-\mathrm{Mn}(\mathrm{Fe})$ compared to only around $300 \mu \mathrm{m}$ after 2 and 5 seconds (Fig. 4). The less steep concentration gradients in $\alpha-\mathrm{Mn}(\mathrm{Fe})$ compared to those in $\gamma$-FeMn may be linked to the aggregation state (i.e. liquid or solid) at high temperature of different parts of the reaction zone.

To get a clear understanding of the state of the reaction zone during the experiment, the Fe/ Mn apparent interdiffusion coefficient was estimated by fitting the measured $\mathrm{Mn}$ profile (in Fig. 4) with the theoretical model proposed by Fick's second law

$$
\begin{gathered}
\frac{\partial C_{\mathrm{Mn}}}{\partial t}=D \nabla^{2} C_{\mathrm{Mn}} \ldots \ldots . . . \\
\frac{C_{\mathrm{Mn}}^{\prime}-C_{\mathrm{Mn}}}{C_{\mathrm{Mn}}^{\prime}-C_{\mathrm{Mn}}^{\circ}}=\operatorname{erf}\left(\frac{x}{2 \sqrt{D t}}\right)
\end{gathered}
$$



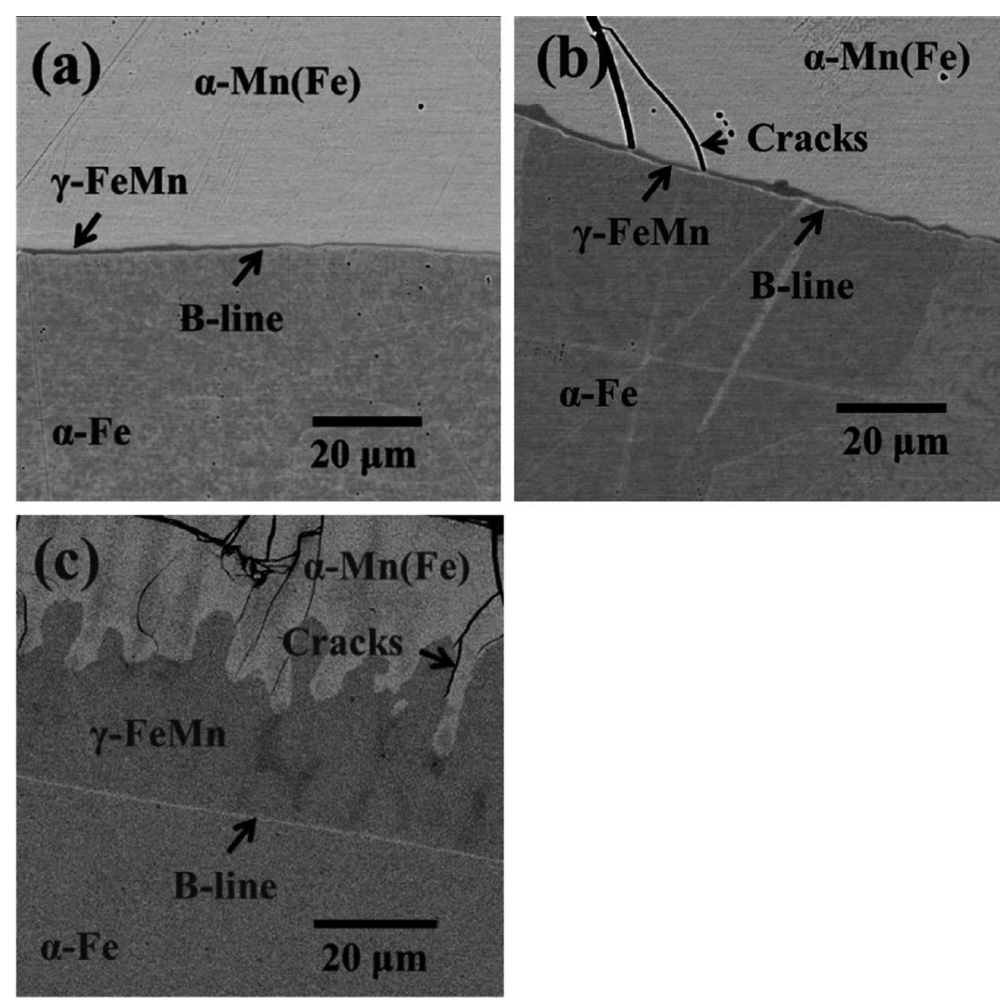

Fig. 3. Interfacial microstructure with interaction time of (a) $2 \mathrm{~s}$; (b) $5 \mathrm{~s}$ and (c) $10 \mathrm{~s}$ in Test 1 (23 ppm [O] in Fe), where Bline represents the bright line.

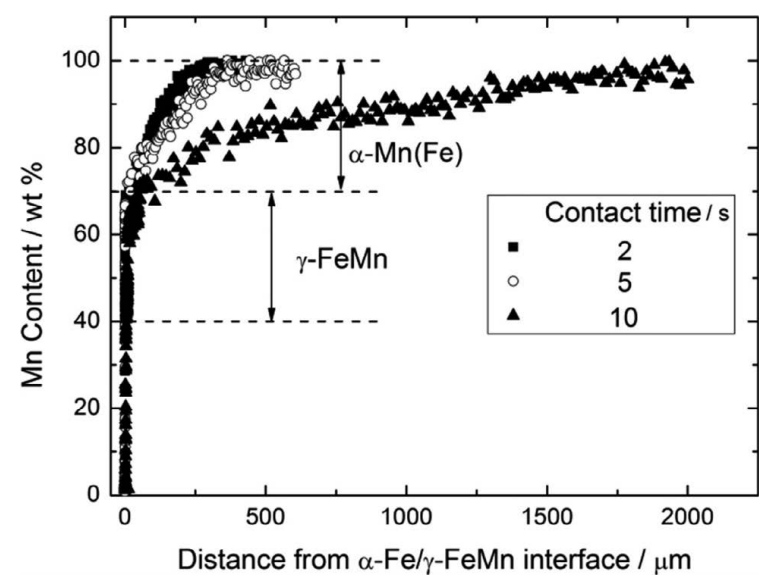

Fig. 4. Mn concentration profiles starting from the $\alpha-\mathrm{Fe} / \gamma-\mathrm{FeMn}$ interface in Tests 1a, b and c measured with EPMA.

Table 3. The total diffusion distance $(\mu \mathrm{m})$, the thickness (Thi in $\mu \mathrm{m})$ and fitted apparent interdiffusion coefficient $(D$ in $\mathrm{m}^{2} / \mathrm{s}$ ) of the sublayers in diffusion couple of Test 1 .

\begin{tabular}{cccccccc}
\hline & \multirow{2}{*}{$\begin{array}{c}\text { Mn content } \\
(\text { wt } \%)\end{array}$} & \multicolumn{2}{c}{ T1-a (2 s) } & \multicolumn{2}{c}{ T1-b (5 s) } & \multicolumn{2}{c}{ T1-c (10 s) } \\
\cline { 3 - 8 } & & Thi & $D$ & Thi & $D$ & Thi & $D$ \\
\hline$\alpha$-Mn(Fe) & $70-100$ & 280 & $4 \times 10^{-9}$ & 370 & $4 \times 10^{-9}$ & 2000 & $2 \times 10^{-8}$ \\
$\gamma-\mathrm{FeMn}$ & $40-70$ & 1 & $4 \times 10^{-14}$ & 2 & $2 \times 10^{-13}$ & 25 & $1 \times 10^{-11}$ \\
\hline Total diffusion $/ \mu \mathrm{m}$ & - & \multicolumn{2}{c}{$\sim 282$} & $\sim 373$ & $\sim 2026$ \\
\hline
\end{tabular}

where $C$ represents the Mn concentration, wt $\% ; C^{\prime}$ and $C^{\circ}$ respectively the Mn concentration at the phase boundary; $t$ the time, s; and $D$ the apparent interdiffusion coefficient, $\mathrm{m}^{2} / \mathrm{s}$, which can be obtained by solving the error function (Eq. (2)). During the calculation, following assumptions and boundary condition are considered and used:

(1). The interdiffusion is driven by the concentration gradient, and there is no convective contribution to mass transport in the tube.

(2). The reaction zone is divided into three sublayers, i.e. the thin bright line, $\alpha-\mathrm{Mn}(\mathrm{Fe})$ and $\gamma$-FeMn. To simplify the calculation, the interdiffusion in the sublayers is assumed to be independent.

(3). For the $\gamma$-FeMn layer, $C_{M n}^{\circ}=40 \mathrm{wt} \%$ and $C_{M n}^{\prime}=70 \mathrm{wt} \%$ at $x_{0}$ (interface between the bright line and the $\gamma$-FeMn layer) and $x^{\prime}(\alpha$-Mn(Fe) $/ \gamma$-FeMn interface $)$, respectively.

(4). For $\alpha-\mathrm{Mn}(\mathrm{Fe})$ layer, $C_{M n}^{\circ}=70 \mathrm{wt} \%$ and $C_{M n}^{\prime}=100 \mathrm{wt} \%$ at $x_{0}=0(\alpha-\mathrm{Mn}(\mathrm{Fe}) / \gamma$-FeMn interface $)$ and $x^{\prime}(\alpha-\mathrm{Mn}(\mathrm{Fe}) / \alpha-$ Mn interface), respectively.

The thickness and fitted apparent interdiffusion coefficients of the sublayers are listed in Table 3. Due to the simplified assumptions as well as the scatter on the experimental points, only the order of magnitude is considered to be relevant. The results show that $D_{\alpha \text {-Mn }}$ is approximately 3 to 5 orders of magnitude larger than $D_{\gamma \text {-FeMn }}$. By comparing these data (Table 3) with literature, ${ }^{18,21-24)}$ it is reasonable to conclude that the $\alpha-\mathrm{Mn}(\mathrm{Fe})$ layer in Fig. 3 is the solidified FeMn melt, which contains a small amount of $\mathrm{Fe}$ and is liquid at the experimental temperature; while the $\gamma$-FeMn layer consists of two contributions: (1) a thin solid $\gamma$-FeMn phase (at experimental temperature) close to pure $\mathrm{Fe}$ and (2) $\mathrm{Fe}-$ Mn melt, which transforms upon quenching into $\gamma$-FeMn. In addition, the apparent interdiffusion coefficient increases with holding time. This is more apparent in the $\gamma$-FeMn layer, where $D$ has increased 3 orders of magnitude by increasing the holding time from 2 to 10 seconds (Table 3 ). This leap in the apparent interdiffusion coefficients implies that the $\gamma$-FeMn layer melts during the experiment due to the 
continuous heat supply from the liquid $\mathrm{Fe}$ and the furnace. In the $\alpha-\mathrm{Mn}(\mathrm{Fe})$ layer, the increase of the apparent interdiffusion coefficient with time is relatively limited, which confirms that this zone is already molten at an early stage.

Based on these considerations and observations with respect to the apparent interdiffusion coefficients and the microstructure of the reaction zone, the proposed development mechanism of the latter is schematically represented in Fig. 5: (a) there is a significant temperature difference between liquid $\mathrm{Fe}\left(1600^{\circ} \mathrm{C}\right)$ and solid $\mathrm{Mn}$ (around $25^{\circ} \mathrm{C}$ at $t=0$, Fig. 5 (a)) before contact. It should be noted that although the $\mathrm{Mn}$ was quickly introduced into the furnace, it was preheated to some extent before contacting the liquid Fe;

(b) a solid Fe shell forms at the initial contact interface with cold Mn (Fig. 5(b), $t=\mathrm{t}_{1}$ ). Meanwhile the solid Mn partly melts due to its low melting temperature $\left(1244^{\circ} \mathrm{C}\right)$;

(c) the interdiffusion of $\mathrm{Fe}$ and $\mathrm{Mn}$ starts, i.e. Fe diffuses into liquid $\mathrm{Mn}$ and $\mathrm{Mn}$ into solid Fe (Fig. 5(c), $t=\mathrm{t}_{2}$ ). As a result of the interdiffusion, $\gamma$-FeMn and liquid layers can form depending on the local Fe content and temperature (see phase diagram in Fig. 2(c)). With time, the solid Fe shell and the $\gamma$-FeMn layer partially melt due to the continuous heat supply from the melt and the furnace;

(d) with a fast quenching, the liquid Fe-Mn melt transforms upon cooling into $\alpha$-Mn(Fe) and $\gamma$-FeMn (Fig. 5(d), $t=\mathrm{t}_{3}$ ) depending on the local Fe content and cooling rate.

\subsubsection{Fe-Mn Diffusion Couple with Oxygen and Sulphur Addition}

The interfacial microstructure of samples of Test 2 with $250 \mathrm{ppm} \mathrm{O}$ and $140 \mathrm{ppm} \mathrm{S}$ addition to the steel is shown in Fig. 6. Compared to the diffusion without $[\mathrm{O}]$ and $[\mathrm{S}]$ addition, plenty of oxysulphide inclusions now form. The formation of $\mathrm{Mn}(\mathrm{O}, \mathrm{S})$ inclusions is believed to be a consequence of the diffusion of $\mathrm{Mn}, \mathrm{O}$ and $\mathrm{S}$ towards the diffusion front, where oxidation and sulphurisation reactions take place, Eqs. (3) and (4). In addition to the $\mathrm{Mn}(\mathrm{O}, \mathrm{S})$ presence in $\gamma$ FeMn, two regions can be distinguished in the Fe-rich side (lower part of Fig. 6): one containing numerous $\mathrm{Fe}(\mathrm{O}, \mathrm{S})$ inclusions and an "inclusion-free" region located between the bulk Fe and the Mn diffusion front. The former results from high [O] and [S] contents in liquid Fe, yielding $\mathrm{Fe}(\mathrm{O}, \mathrm{S})$ upon solidification. The inclusion free zone suggests locally lower [O] and [S] contents at high temperature compared to the bulk Fe. The extent of Fe with low [O] and [S] contents determines the thickness of the inclusion-free zone. As most of the mass transport under the experimental conditions is assumed to be driven by diffusion, a thin inclusion-free zone corresponds to a steep [O] and [S] concentration profile near the diffusion front. As can be seen from

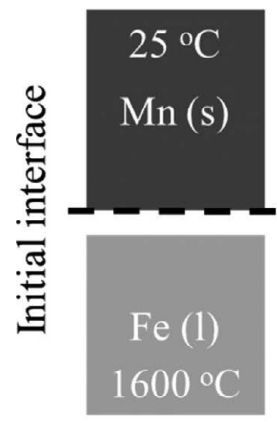

(a) $t=0$

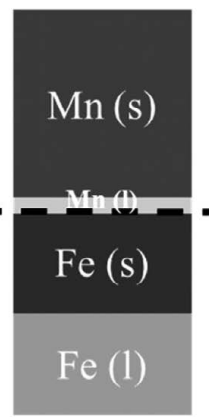

(b) $t=\mathrm{t} 1$

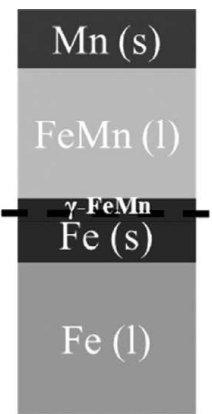

(c) $t=\mathrm{t} 2$

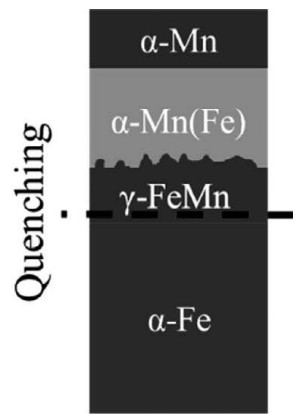

(d) $t=\mathrm{t} 3$

Fig. 5. Schematic evolution of the reaction zone.
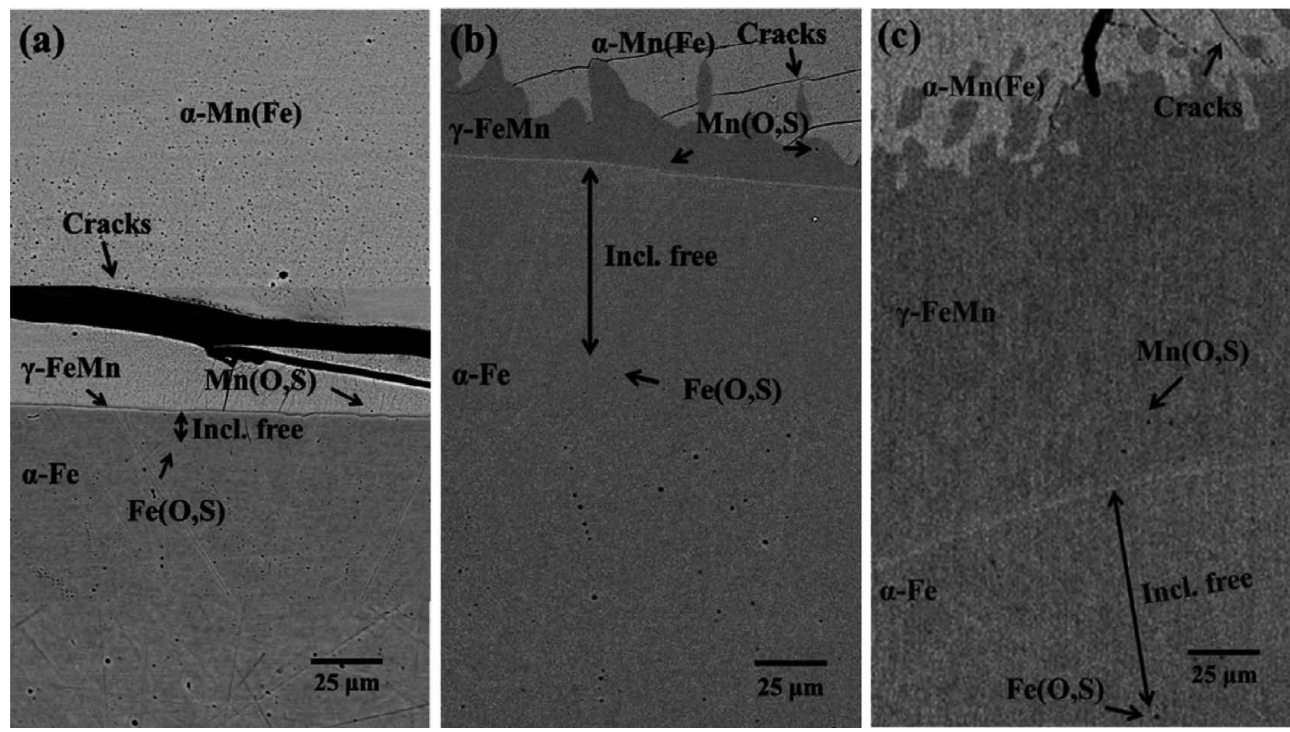

Fig. 6. Interfacial microstructure with interaction time of (a) $2 \mathrm{~s}$; (b) $5 \mathrm{~s}$ and (c) $10 \mathrm{~s}$ in Test 2 (250 ppm [O] and 140 ppm $[\mathrm{S}]$ in $\mathrm{Fe})$. 
Fig. 6, the thickness of this zone varies with holding time: after $2 \mathrm{~s}$ this zone is around $10 \mu \mathrm{m}$ thick (Fig. 6(a)), whereas it reaches about $66 \mu \mathrm{m}$ and $91 \mu \mathrm{m}$, after $5 \mathrm{~s}$ (Fig. 6(b)) and $10 \mathrm{~s}$ (Fig. 6(c)) respectively.

$$
\begin{array}{r}
\mathrm{Mn}+[\mathrm{O}]=\mathrm{MnO} \\
\mathrm{Mn}+[\mathrm{S}]=\mathrm{MnS} \ldots \ldots . . . \\
\Delta_{\mathrm{M}(\mathrm{O}, \mathrm{S})}^{\circ}=\frac{[\mathrm{M}][\mathrm{O}][\mathrm{S}]}{[\mathrm{M}]^{\mathrm{eq}}[\mathrm{O}]^{\mathrm{eq}}[\mathrm{S}]^{\mathrm{eq}}}
\end{array}
$$

where $\Delta_{\mathrm{M}(\mathrm{O}, \mathrm{S})}^{\circ}$ represents the local supersaturation of $\mathrm{M}(\mathrm{O}, \mathrm{S}), \mathrm{M}=\mathrm{Fe}$ or $\mathrm{Mn} ;[\mathrm{M}]$ and $[\mathrm{M}]^{\mathrm{eq}}$ are respectively the local $\mathrm{M}$ and the equilibrated $\mathrm{M}$ concentration.

To help the understanding of the formation of the inclusion free region, Fig. 7 shows a schematic of the reaction zone. The overlap between the $\mathrm{Mn}$ and [O] (and [S]) concentration profiles and the build-up of the supersaturation curve in the reaction zone at experimental temperature near the diffusion front is drawn. There are two reaction fronts, at which the $\mathrm{Fe}(\mathrm{O}, \mathrm{S})$ and $\mathrm{Mn}(\mathrm{O}, \mathrm{S})$ inclusions are found respectively. According to homogeneous nucleation theory, the supersaturation $\Delta^{\circ}$ of inclusions (Eq. (5)) must reach a critical value $\Delta^{*}$ to initiate new nuclei. ${ }^{3,8,25)}$ The reaction front appears when $\Delta^{\circ}$ reaches $\Delta^{*}$. Once nucleation occurs at the reaction front, supersaturation is rapidly consumed by inclusion formation, and the [O] and/or [S] decrease to their equilibrium contents at the reaction fronts. Immediately after contact, the liquid Fe is solidified and due to the high $[\mathrm{O}]$ and $[\mathrm{S}]$ contents in the $\mathrm{Fe}$ melt, $\mathrm{Fe}(\mathrm{O}, \mathrm{S})$ inclusions are formed in the solidified Fe. On the other hand, the [O] and [S] react with $\mathrm{Mn}$ once the critical supersaturation of $\mathrm{Mn}(\mathrm{O}, \mathrm{S})\left(\Delta_{\mathrm{Mn}(\mathrm{O}, \mathrm{S})}^{*}\right)$ is reached, forming $\mathrm{Mn}(\mathrm{O}, \mathrm{S})$ inclusions at the $\mathrm{Fe} / \mathrm{Mn}$ interface. The reaction results in a concentration gradient of $[\mathrm{O}]$ and [S], and consequently their diffusion from bulk Fe towards the reaction zone, leading to a decrease of [O] and [S] contents in the solidified Fe. At high temperature, the $\mathrm{Fe}(\mathrm{O}, \mathrm{S})$ inclusions are not stable and tend to dissolved again in this [O] and [S] depleted (low) region once the supersaturation $\left(\Delta_{\mathrm{Fe}(\mathrm{O}, \mathrm{S})}^{\circ}\right)$ is below 1. As shown in Fig. 7, an "inclusion free" region forms between the reaction front of dissolving $\mathrm{Fe}(\mathrm{O}, \mathrm{S})$ and that of forming $\mathrm{Mn}(\mathrm{O}, \mathrm{S})$. Due to the larger diffusivity of $[\mathrm{O}]$ and $[\mathrm{S}]$ in solidified $\mathrm{Fe}$

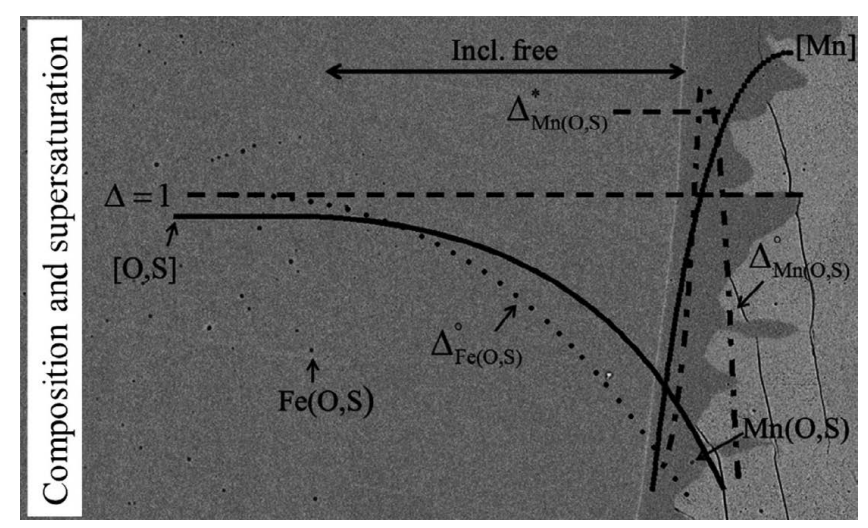

Fig. 7. Schematic of the inclusion free zone formation, where solid [Mn], [S] and [O] lines represent their concentration; $\Delta_{\mathrm{Fe}(\mathrm{O}, \mathrm{S})}^{\circ}$ and $\Delta_{\mathrm{Mn}(\mathrm{O}, \mathrm{S})}^{\circ}$ respectively the local supersaturation of $\mathrm{Fe}(\mathrm{O}, \mathrm{S})$ and $\mathrm{Mn}(\mathrm{O}, \mathrm{S}) ; \Delta_{\mathrm{Mn}(\mathrm{O}, \mathrm{S})}^{*}$ the critical supersaturation for $\mathrm{Mn}(\mathrm{O}, \mathrm{S})$ nucleation and $\Delta=1$ the equilibrium condition. than that of $\mathrm{Mn}$, the reaction front of $\mathrm{Fe}(\mathrm{O}, \mathrm{S})$ dissolution moves faster than that of $\mathrm{Mn}(\mathrm{O}, \mathrm{S})$ formation. ${ }^{26,27)}$ With increasing interaction time, the diffusion of [O] and [S] from bulk $\mathrm{Fe}$ to the reaction zone proceeds, enlarging the area in the solid Fe with low [O] and [S] contents, and consequently resulting in a larger inclusion free zone. This agrees with the experimental observation in Fig. 6 that the thickness of the inclusion free zone increases over time.

Next to the inclusion free zone, $\gamma$-FeMn is also observed in qualitative similarity with the $\mathrm{Fe}-\mathrm{Mn}$ diffusion couples without extra [O] and [S] additions (i.e. Test 1). Initially, i.e. after 2 seconds, a thin $\gamma$-FeMn zone is observed (Fig. 6(a) around $1 \mu \mathrm{m}$ ), which grows to 30 and $118 \mu \mathrm{m}$ after 5 (Fig. 6(b)) and 10 seconds (Fig. 6(c)), respectively. The latter is much thicker than in Tests 1-b and 1-c (Figs. 3(b) and 3(c)), indicating that the reaction zone is significantly influenced by [O] and [S] addition.

\subsection{Effect of Oxygen and Sulphur Contents}

\subsubsection{The Observed Interfacial Structure as a Function of} Oxygen and Sulphur Content

Figures 8 (5 s interaction, Tests 1-b, 3, 4 and 5) and 9 (10 s interaction, Test 6) compare the interfacial microstructure for various [O] and [S] contents in liquid Fe. Similar with Tests 1 and 2, three phases, i.e. $\alpha$-Mn(Fe), $\gamma$-FeMn and $\alpha$-Fe are identified. By comparing Tests 1-b and 5, it is clear that for a constant holding time and [O] content ( 5 seconds and 23-34 ppm [O]), the thickness of $\gamma$-FeMn remains at a similar level (around $2 \mu \mathrm{m}$ in Figs. 8(a) and 8(b)) even though the [S] content has increased from 0 to $505 \mathrm{ppm}$. This suggests that the $[\mathrm{S}]$ has limited influence on $\mathrm{Fe} / \mathrm{Mn}$ stability regions of different phases. However, for a constant holding time and [S] (Figs. 8(a) and 8(c), i.e. Test 1-b vs Test 4, $5 \mathrm{~s}$ and 0 ppm [S]); Figs. 8(d) and 8(b), i.e. Test 3 vs Test 5, $5 \mathrm{~s}$ and 450-500 ppm [S]), the thickness of $\gamma$ FeMn differs strongly with varying $[\mathrm{O}]$ content. High $[\mathrm{O}]$ in the melt leads to a thick $\gamma$-FeMn zone and a rough or irregular $\gamma$-FeMn $/ \alpha$-Mn(Fe) interface. With extremely high oxygen $(1660 \mathrm{pm})$ and sulphur (3 $900 \mathrm{ppm})$ addition (i.e. Test 6 in Fig. 9), a thick $\gamma$-FeMn layer (approximately $1000 \mu \mathrm{m}$ ) was formed after quenching, and a large number of detached $\gamma$-FeMn fragments were found in the $\alpha-\mathrm{Mn}(\mathrm{Fe})$ matrix. This confirms that high [O] leads to a large liquid reaction zone, resulting in fast $\mathrm{Fe} / \mathrm{Mn}$ interdiffusion and a thick $\gamma$-FeMn layer upon solidification. On the other hand, Figs. 8 and 9 show that the thickness of the inclusion free zone decreases with increasing sum of [O] and [S] contents in the melt. In the following section, a fundamental analysis to understand the above observations (i.e. influences of oxygen and sulphur on the $\mathrm{Fe} / \mathrm{Mn}$ interaction) will be given based on the measured Mn concentration profile and the calculated reaction heat exchange at the interface.

\subsubsection{Influence on $\gamma$-FeMn Formation}

Figure 10 summarizes the thickness of $\gamma$-FeMn (Fig. 10(a)) and the fitted apparent interdiffusion coefficients (Fig. 10(b)) as a function of [O] content in the melt. The thickness of $\gamma$-FeMn increases with [O] addition. This has been further corroborated by comparing the Mn profiles (at the Fe/Mn diffusion interface, Fig. 11) of samples with various $[\mathrm{O}]$ in liquid Fe. It is clear that the total diffusion length 


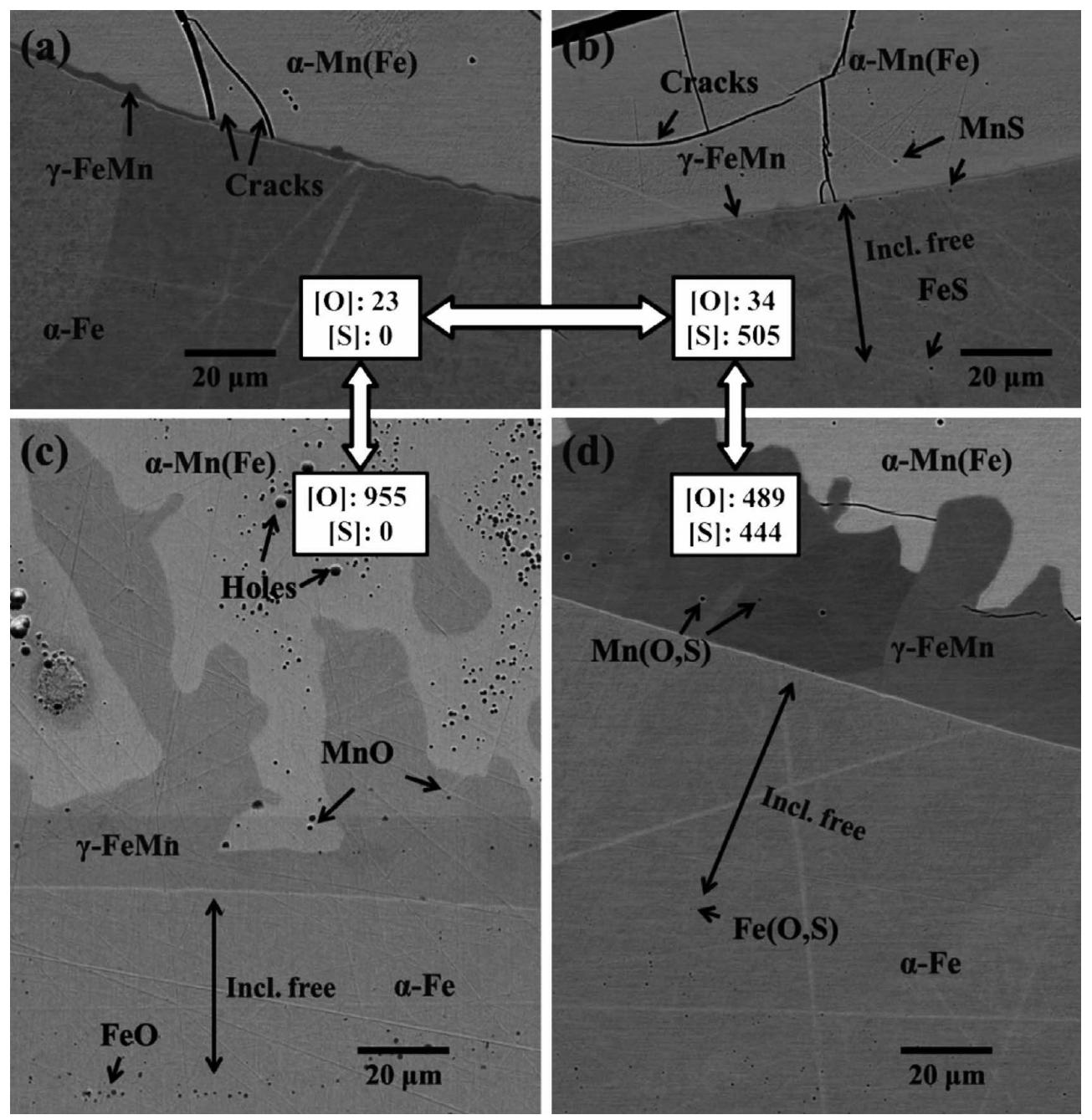

Fig. 8. Interfacial microstructure for different oxygen and sulphur additions after 5 seconds interaction: (a) Test 1-b; (b) Test 5; (c) Test 4 and (d) Test 3.

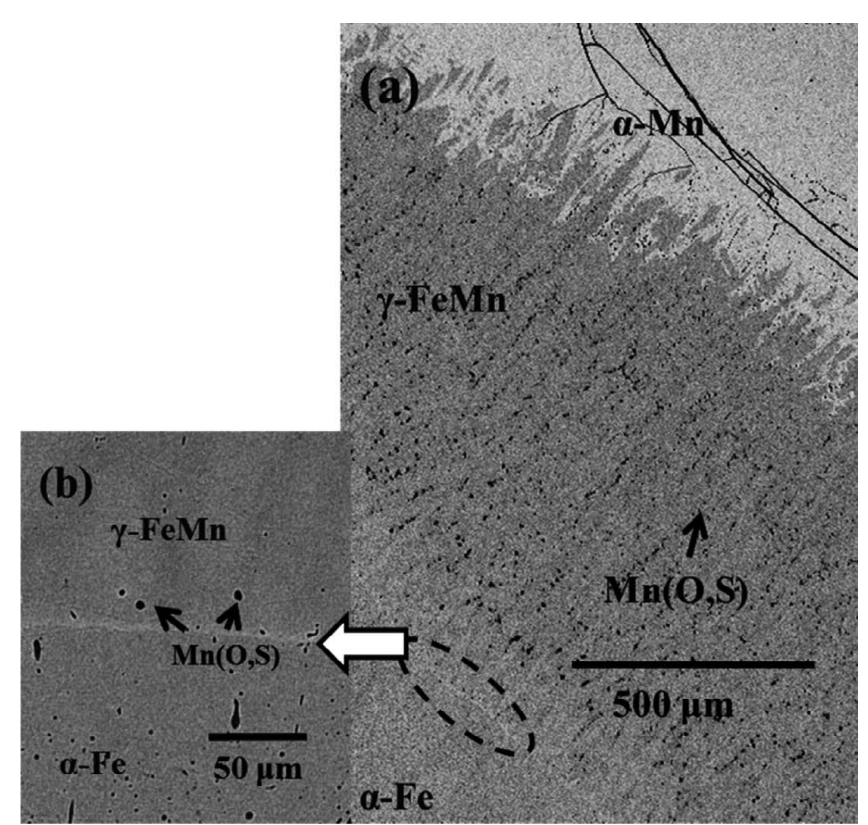

Fig. 9. Interfacial miscostructure of Test 6 with $[\mathrm{O}]=1600$ and $[\mathrm{S}]=3600 \mathrm{ppm}$ after $10 \mathrm{~s}$ holding.

(consisting of $\alpha$-Mn(Fe) and $\gamma$-FeMn layers) changes with holding time, but not with oxygen content (see Fig. 11(b) around $2000 \mu \mathrm{m}$ ). The total diffusion length, here the pene-

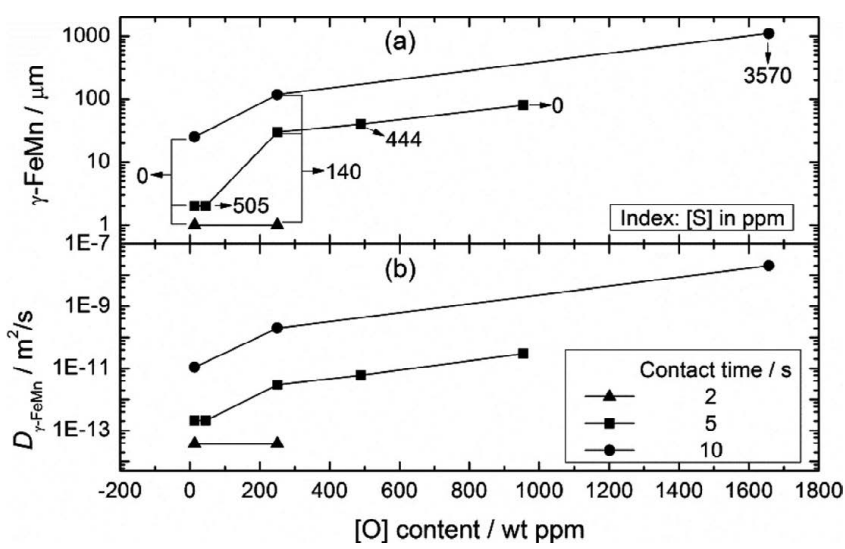

Fig. 10. (a) $\gamma$-FeMn thickness and (b) fitted apparent interdiffusion coefficient as a function of [O] content in the liquid Fe.

tration depth of Fe, roughly corresponds to the thickness of the liquid zone sandwiched between the solidified Fe and solid Mn. The liquid/solid interface at the Mn side is primarily determined by the melting rate of pure $\mathrm{Mn}$, which is completely heat controlled. Since [O] is the amount of dissolved oxygen in the Fe melt and it reacts with Mn only around the Mn diffusion front, i.e. solid Fe and $\gamma$-FeMn interface, it would not influence the melting rate of the pure $\mathrm{Mn}$.

The increase in $\gamma$-FeMn thickness with [O] should be 

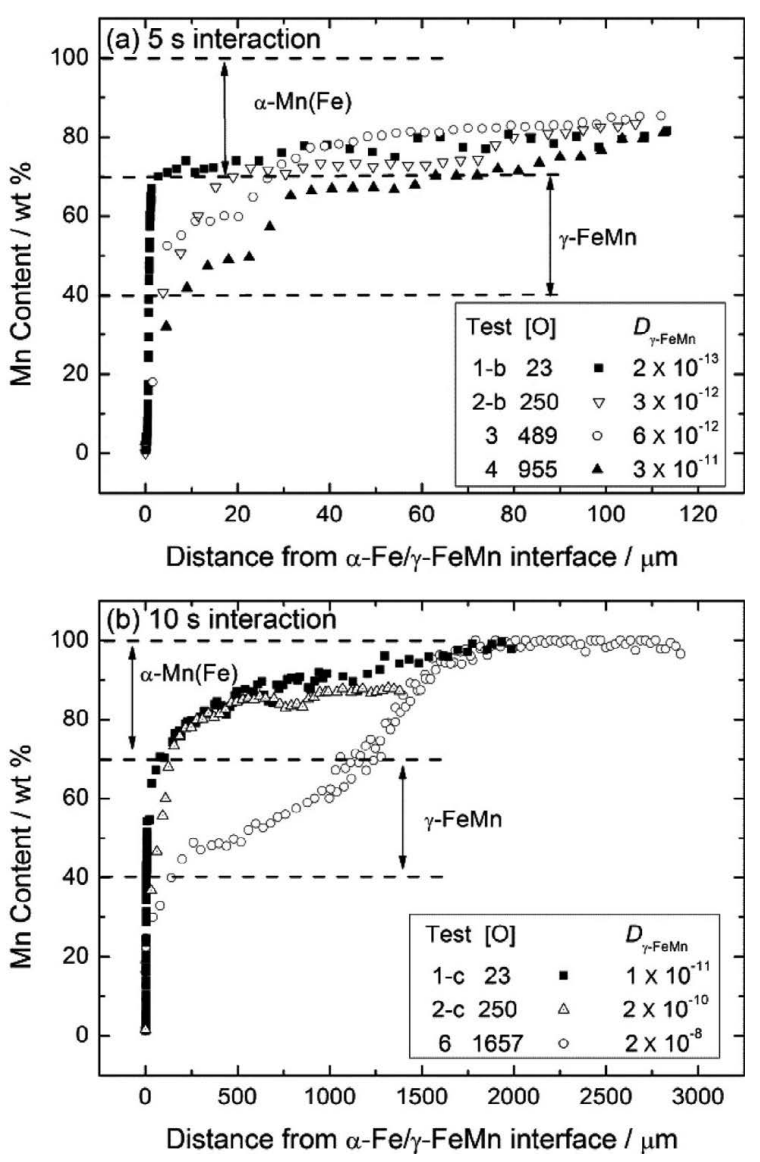

Fig. 11. Mn profile at the diffusion interface for various [O] contents in liquid Fe after (a) $5 \mathrm{~s}$ and (b) $10 \mathrm{~s}$ interaction.

related to its influence on the mass transport. Figure 11 shows a less steep Mn concentration profile with increase in [O], indicating enhanced Fe/Mn interdiffusion. By fitting the measured $\mathrm{Mn}$ concentration value with the theoretical model based on Fick's second law (Eqs. (1) and (2)), the apparent interdiffusion coefficient $\left(D_{\gamma \text {-Fe/Mn }}\right)$ for different $[\mathrm{O}]$ levels was estimated and shown in the lower part of Fig. 10. Similar with the evolution of the $\gamma$-FeMn thickness, the apparent interdiffusion coefficients strongly increase with oxygen addition. The leap of apparent diffusion coefficient is believed to be linked with the aggregation state (i.e. liquid or solid) of the diffusion zone with different [O] levels at high temperature.

To understand the influence of $[\mathrm{O}]$ and $[\mathrm{S}]$ on the reaction zone development, the liquid/solid ratio at the reaction zone was calculated (with the aid of FactSage, using databases FactPS, FSstel and FToxid) as functions of [O] and [S] contents. In the calculation, $1 \mathrm{~g}$ liquid $\mathrm{Fe}$ with various $[\mathrm{O}]$ and [S] contents $\left(1600^{\circ} \mathrm{C}\right)$ is equilibrated with $0.5 \mathrm{~g} \mathrm{Mn}\left(25^{\circ} \mathrm{C}\right)$. The total enthalpy change is set to zero to obtain the adiabatic system temperature after reaction. The resulting liquid/ solid ratio of the equilibrated products is shown in Fig. 12. This ratio rises substantially with increasing [O] and [S] contents in liquid Fe. The effect of [O] is much more pronounced than that of $[\mathrm{S}]$, which is in agreement with the experimental observations (Fig. 8). Based on the calculated results in Fig. 12, the liquid/solid ratio after reaction is expected to rise from 1 to $20 \%$ as the [O] changes from 0 to $1660 \mathrm{ppm}$. This explains the leap in calculated apparent

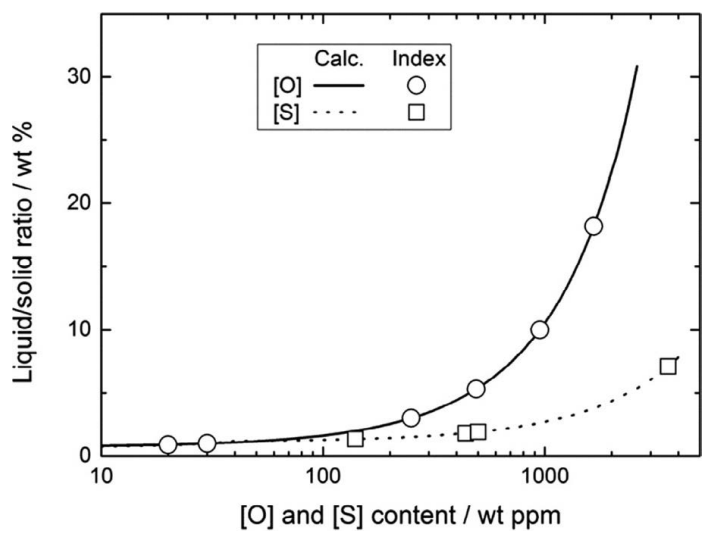

Fig. 12. Influence of $[\mathrm{O}]$ and $[\mathrm{S}]$ content on liquid/solid ratio after reacting $1 \mathrm{~g} \mathrm{Fe}\left(1600^{\circ} \mathrm{C}\right)$ with $0.5 \mathrm{~g} \mathrm{Mn}\left(25^{\circ} \mathrm{C}\right)$ as calculated with FactSage, index points can be used to read the predicted liquid/solid ratio at the experimental [O] and [S] contents.

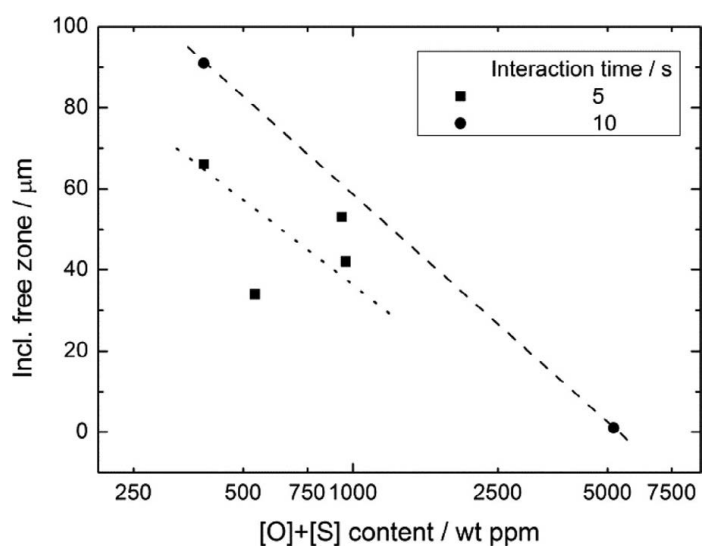

Fig. 13. The evolution of inclusion free zone thickness as a function of the sum of $[\mathrm{O}]+[\mathrm{S}]$ content in liquid $\mathrm{Fe}$, where the dashed lines indicate the evolution tendency.

interdiffusion coefficients shown in the lower part of Fig. 10 , i.e. $D_{\gamma \text {-FeMn }}$ increased 3 orders of magnitude by increasing [O] from 23 to $1660 \mathrm{ppm}$. The contribution of [O] and [S] to the increase in the liquid/solid ratio is likely related to exothermic Mn oxidation/sulphurization reactions (Eqs. (3) and (4) $)^{25,27)}$ at the Fe/Mn interface. In other words, the Mn oxidation and sulphurization reactions generate heat and raise the temperature at the initial $\mathrm{Fe} / \mathrm{Mn}$ interface, forming more liquid phase. The later facilitates the Fe/Mn interdiffusion process, finally enhancing the $\gamma$-FeMn formation upon quenching.

\subsubsection{Influence on the Inclusion Free Zone Thickness}

As seen in Fig. 13, the thickness of the inclusion-free zone generally decreases (not necessarily linear) with the sum of [O] and [S] content for a given interaction time. As discussed in section 3.2 (Fig. 7), the inclusion formation of $\mathrm{Fe}(\mathrm{O}, \mathrm{S})$ and $\mathrm{Mn}(\mathrm{O}, \mathrm{S})$ is believed to be a consequence of the diffusion of $\mathrm{Mn}, \mathrm{O}$ and $\mathrm{S}$ towards the diffusion front, where oxidation and sulphurisation reactions take place. Therefore, transport and consumption of [O], [S], Mn and Fe determine the extent of inclusion-free zone formation. With high $\mathrm{O}$ and $\mathrm{S}$ contents, only a limited part of [O] and [S] can be consumed through the reactions with $\mathrm{Mn}$ at the 
reaction front, and the remaining [O] and [S] are still high enough for $\mathrm{Fe}(\mathrm{O}, \mathrm{S})$ inclusions to be present, leading to a narrow inclusion free zone. At extremely high [O] and [S] contents (1 600 ppm O and 3900 ppm S), no inclusion free zone forms, as seen in Fig. 9. It should be noted that the heat release due to the oxidation and sulphurisation reactions will also influence the $[\mathrm{O}]$ and $[\mathrm{S}]$ diffusion in solidified $\mathrm{Fe}$ and consequently will affect the thickness of the inclusion free zone.

\subsection{Comparison with Previous Studies}

Van Ende et al. investigated the interfacial reactions between cold $\mathrm{Al}$ additions and liquid $\mathrm{Fe}$ by using a similar liquid metal suction method. ${ }^{11,12)}$ They did not establish the liquid or solid nature of the layers ( $\mathrm{FeAl}$ and $\alpha-\mathrm{Fe}(\mathrm{Al})$ ) adjacent to the Fe shell. In the present paper, by fitting the apparent diffusion coefficient, the layer of $\gamma$-FeMn in the quenched diffusion couple is found to consist of a thin solid $\gamma$-FeMn and solidified Fe-Mn melt. In other words, this layer contains both liquid and solid fractions at experimental temperature. What's more, they reported that the inclusion free zone was in liquid state at experimental temperature. ${ }^{11,12)}$ According to the present observations and calculations (Figs. 5 and 7) however, the inclusion free zone is most likely formed in the solidified Fe shell. The calculation results show that the presence of oxygen in liquid $\mathrm{Fe}$ enhances the internal diffusion by locally raising the temperature at the initial $\mathrm{Fe} / \mathrm{Mn}$ interface.

\section{Conclusion}

The interfacial reactions between cold Mn and liquid Fe containing various amounts of oxygen and sulphur were investigated with quenched $\mathrm{Fe}-\mathrm{Mn}$ diffusion couples. The formation of alloy phases and their growth driven by interdiffusion was discussed. The influence of interaction time, dissolved oxygen and sulphur on the interdiffusion and formation of an inclusion free zone was quantitatively evaluated. The main results are summarized as follows:

(1) Three phases are identified in the quenched Fe-Mn diffusion couple, i.e. $\alpha$ - $\mathrm{Mn}(\mathrm{Fe}), \gamma$-FeMn and $\alpha$-Fe. The thickness of $\alpha-\mathrm{Mn}(\mathrm{Fe})$ and $\gamma$-FeMn increased with interaction time.

(2) The fitted $D_{\alpha-\mathrm{Mn}(\mathrm{Fe})}$ in the quenched samples indicates that the $\alpha-\mathrm{Mn}(\mathrm{Fe})$ layer is the solidified Fe-Mn melt, which contains a small amount of $\mathrm{Fe}$ and is liquid at the experimental temperature. The small $D_{\gamma \text {-FeMn }}$ and its significant increase during the experiment indicate that the $\gamma$-FeMn layer consists of two contributions: a thin $\gamma$-FeMn phase which is solid at experimental temperature and a $\mathrm{Fe}-\mathrm{Mn}$ melt which transforms upon quenching into $\gamma$-FeMn.

(3) Based on these apparent interdiffusion coefficients and the microstructure of the reaction zone, the latter's development mechanism is proposed. The liquid Fe solidified immediately after contacting the cold Mn. Meanwhile Mn melts due to its low melting temperature. Thereafter, Fe/ $\mathrm{Mn}$ interdiffusion results in the formation of a FeMn interdiffusion layer. This reaction zone can be partially solid and liquid.

(4) Oxygen and sulphur additions locally raise the temperature by releasing chemical heat of oxidation and sulphurisation, consequently increasing the apparent interdiffusion coefficient of $\mathrm{Fe} / \mathrm{Mn}$ at the $\alpha$-Fe $/ \gamma$-FeMn interface, enhancing internal dissolution.

(5) An inclusion free zone is observed in the inner part of the Fe shell. With oxygen and sulphur addition, its thickness decreases, and it disappears for extremly high [O] and $[\mathrm{S}]$ contents $([\mathrm{O}]>1600$ and $[\mathrm{S}]>3600 \mathrm{ppm})$. Its formation is believed to be due to a local depletion of $\mathrm{O}$ and $\mathrm{S}$, caused by the diffusion of $\mathrm{Mn}, \mathrm{S}$ and $\mathrm{O}$ and oxidation/sulphurisation reactions at the diffusion front.

\section{REFERENCES}

1) Y. N. Dastur and W. C. Leslie: Metall. Trans. A, 12 (1981), 749.

2) I. Tsukatani, S. Hashimoto and T. Inoue: ISIJ Int., 31 (1991), 992.

3) H. Ohta and H. Suito: Metall. Mater. Trans. B, 27 (1996), 263.

4) M. Wakoh, T. Sawai and S. Mizoguchi: Tetsu-to-Hagané, 78 (1992), 1697.

5) H. Kim, H. Lee and K. Oh: Metall. Mater. Trans. A, 32 (2001), 1519.

6) D. Zhang, H. Terasaki and Y. Komizo: Acta Mater., 58 (2010), 1369.

7) A. Šalak, M. Selecká and R. Bureš: Powder Metall. Prog., 1 (2001), 41.

8) H. Suito and H. Ohta: ISIJ Int., 46 (2006), 33.

9) S. A. Argyropoulos and R. I. L. Guthrie: Can. Metall. Q., 18 (1979), 267.

10) S. A. Argyropoulos and R. I. L. Guthrie: Metall. Mater. Trans. B, 15 (1984), 47.

11) M. Van Ende, M. Guo, J. Proost, B. Blanpain and P. Wollants: ISIJ Int., 50 (2010), 1552.

12) M. Van Ende, M. Guo, J. Proost, B. Blanpain and P. Wollants: ISIJ Int., 51 (2011), 27.

13) L. Pandelaers, D. Barrier, P. Gardin, P. Wollants and B. Blanpain: Metall. Mater. Trans. B, 44 (2013), 561.

14) M. M. Pande, M. Guo and B. Blanpain: ISIJ Int., 53 (2013), 629.

15) T. B. Massalski, H. Okamoto, P. R. Subramanian and L. Kacprzak: Binary Alloy Phase Diagram, ASM International, Metals Park, OH, (1986).

16) J. Stewart and R. Cywinski: J. Phys. Condens. Mater., 11 (1999), 7095 .

17) J. Jun and C. Choi: Mater. Sci. Eng. A, 252 (1998), 133.

18) A. T. W. Kempen, F. Sommer and E. J. Mittemeijer: Acta Mater., 50 (2002), 3545.

19) D. Pierre, J. C. viala, M. Peronnet, F. Bosselet and J. Bouix: Mater. Sci. Eng. A, 349 (2003), 256.

20) E. Gartstein and A. Rabinkin: Acta Metall., 27 (1979), 1053.

21) W. Huang: Calphad, 13 (1989), 243.

22) R. Taylor and R. Krishna: Multicomponent Mass Transfer, John Wiley and Sons, New York, (1993).

23) F. Calderon, N. Sano and Y. Matsushita: Metall. Mater. Trans. B, 2 (1971), 3325.

24) E. Turkdogan: Fundamentals of Steelmaking, Maney Materials Science, London, (1996).

25) K. Wasai and K. Mukai: Metall. Mater. Trans. B, 30 (1999), 1065.

26) M. Dzugutov: Nature, 381 (1996), 137.

27) A. Dimanov and M. Wiedenbeck: Eur. J. Mineral., 18 (2006), 705. 